a recent report from the University of Indonesia, of the 2,000 registered students in the Faculty of Engineering for the year in question, 1,300 were in the first year, a dozen or so in the fifth or final year and only one graduated.

The considerations noted by Sir Sydney imply that by its very nature the task of education for development must fall in the main upon the under-developed countries themselves, and in this connexion he stressed the importanee of the 30,000 overseas students in the United Kingdom, the great majority of whom come from under-developed countries, while a high proportion of these are privately financed. Nevertheless, the developed countries have a most important part to play, particularly at the level of university and technical training, but their own specialized man-power difficulties set strict limits to what they can do ; and Sir Sydney commented that the London School of Economics has every year to reject a high percentage of applications from abroad for higher degree studies because it, has reached the limit of the numbers which its teaching staff can effectively supervise. The resources to be shared with the less advanced countries are not solely finances but above all highly trained men and women; and this is already being done by numerous agencies. Besides the great help given by British universities, through their organization as well as by offering places to overseas students, more than $£ 29$ million has been contributed during the decade 1946-56 by the British taxpayer to overseas students and education through the British Council and Colonial Development and Welfaro Funds.

As the fruit of these and earlier efforts, there are now in British Colonies or former Colonial dependencies four universities, five university colleges and various other institutes of higher education. The Colombo Plan, which is essentially a collective name for various loosely co-ordinated pieces of mutual assistance by one Commonwealth country to another, has brought to numerous individuals in the underdeveloped areas opportunities of study overseas and grants of assistance to educational institutions. Commonwealth countries are also helping in ways quite outside the Colombo Plan, while many countries have received considerable aid to education under American foreign aid programmes. There is also the substantial help given by the Rockefeller Foundation and other private foundations, particularly for the initiation of new projects; and on the international plane much is being done through the Technical Assistance Board of the United Nations, through the United Nations Educational, Scientific and Cultural Organization and in specifically technical fields by the other specialized agencies such as the Food and Agriculture Organization and the World Health Organization.

Both the finance and technical personnel required for all this come in the main from the developed countries, and in this connexion Sir Sydney urged the importance of doing everything possible to ensure that British people who undertake a period of service abroad do not thereby damage their prospects for appointments in Britain. Something more could also be done to encourage the exchange of books and periodicals and the movements of scientists and other learned men. This is still liable to be hindered by political considerations even in non-Communist countries, and Sir Sydney fears that there is a danger of a system of exclusion of books and periodicals arising in non-Communist under-developed areas. Every effort should be made to assist people from under developed countries to attend meetings of learned societies and to ensure that the problems of these countries receive attention at such meetings; Sir Sydney also suggested that the production in a single language appropriate to a particular area of summaries of scientific publications in diverse languages would be a very fruitful piece of international co-operation.

Such projects can scarcely become effectivo, however, unless the less-developed countries refrain from accentuating difficulties by exaggerating political, linguistic and psychological obstacles. If, however, the developed countries use to the full their opportunities for initiative in sharing their educational resources along such lines as Sir Sydney Caine indicates, that in itself would encourage the growth of mutual tolerance and goodwill. There would, nevortheless, appear to be a wide field in which professional societies could support what the universities and many educational institutions are already doing, not only to encourage the growth of such an atmosphere of goodwill, but also, and no less important, to assist the wisest and most effective use of the most precious of all resources, in developed and under-developed countries alike that of trained men and women.

\section{BIOLOGICAL RHYTHMS}

$A^{\mathrm{T}}$ if the sixth conference of the Society for Biological Rhythms, held on the Semmering, near. Vienna, during August 26-28, thirty-six papers were presented by members and guests from eleven countries. They were welcomed by Dr. E. Dissmann (Klagenfurt), the local secretary.

The main theme of the opening session organized by Prof. A. Jores (Hamburg) was "Time in Biology", which was covered by six invited speakers. $H$. Laurell (Halmsted) critically discussed ancient and modern ideas of time, and contrasted its physical, physiological and psychological aspects; he also reviewed methods of measuring time. J. Aschoff (Heidelberg) elaborated the idea of time-eues or clues (Zeitgeber), namely, those periodical factors, external to a rhythmic system, which can be shown experimentally to control its phase. He demonstrated that in constant conditions of temperature and illumination and in the absence of noise or mechanical disturbance, $24 . \mathrm{hr}$. patterns in the motor activity of vertebrates persist but gradually fall out of step, thus indicating that all external time-cues have been successfully eliminated. By reintroducing these potential cues one at a time their relative efficacy can be assessed. H. Kalmus (University College, London) observed that all life is accompanied by an incessant redistribution of material in space and time, and thus defined the investigation of biological rhythms as a study of the synchronization of mechanisms of transport. The appearance of any biological material at the 'right' time and at the 'right' site can be interpreted as a homoostatic: arrangement brought about by the remote causes of selection, but must also be explained by the operation of physiological cues at any particular time. The opportunist nature of selection and the complexities of biological organization frequently produce nonoptimal time adaptrations and limited adaptability. 
Dissociation of time-cues and internally established rhythms, such as those brought about by night work or air travel, may thus cause serious disturbances. Sir Nigel Ball (London) stressed the advantages, for bio-rhythmic studies, of plants over animals, in so far as the former lack the complications of a central nervous system. Using infra-red photographs he showed the extension growth of oat coleoptiles to be governed by a rhythm of approximately $24 \mathrm{hr}$. duration; this he could induce by transferring seedlings from light to darkness, and he could retard it by lack of oxygen. The rhythm persisted even after the removal of the tip of the coleoptile. In a more general way, Sir Nigel discussed the establishment and synchronization of rhythms in single elements and aggregates, and contended that the functional significance of the endogenous rhythms widely found in plants still remains obscure. F. Halberg (Minneapolis) surveyed many examples of physiological functions dependent upon time, and E. von Stockert (Rostock) gave a lively account of disturbances in the time sense and time consciousness of psychotic patients.

The six speakers at the opening session then formed a panel for a joint discussion of "Time in Biology", together with speakers from the floor. Also discussed was a lecture by J. Wilder (New York) concerning the relevance of that author's law of initial values for the interpretation of certain apparently rhythmic biological phenomena. J. Ježić (Sarajevo) claimed that, in the growth and decay of biological systems, cycles are best described by parabolas, and indicated some practical uses for such a concept.

The shorter papers of the later sessions were loosely grouped according to subject-matter or method. The 24-hr. periodicity of division in normal and malignant cells was discussed by F. Halberg, E. Halberg and J. J. Bittner (Minneapolis), and the implications for bioassay of daily fluctuations by $\mathrm{F}$. Vering (Vienna). Daily fluctuations of bodily functions and their clinical importance were discussed by J. Blume (Düsseldorf), who exemplified the mathematical problems by analysing some of Kleitman's temperature curves during and after regimens in artificial light with periods of twenty-one and twontyeight hours; W. Menzel (Hamburg) demonstrated variations in the interdependence in health and disease of the 24-hr. rhythm of rectal temperature, urine volume and concentration of chloride, urea and creatinine.

Ch. Kris (Cambridge, Mass.) presented results showing correlations between numerous performance tests and physiological measurements in respect of diurnal and menstrual rhythms, and described an objective measure of physiological age derived from her measurements. The biological age of man was also discussed by M. B. J. Nadel (Herzlia, Israel), and H. U. Ziolko (Berlin), who described disturbed day/ night rhythms of vegetative functions in neurotic patients, and tried to explain some of their peculiar experiences during sleep as consequences of disturbed synchronization. S. Gifford (Boston) considered the developments of the pattern of sleep and wakefulness in infants from the point of view of a psychoanalyst, and $T$. H. Hellbrügge (Munich) treated the subject from the point of view of the physiologist. M. B. Ischlondsky (New York) dealt with the harm which may be caused by stimulation during 'inhibitory phases' of the human central nervous system, a factor which he holds responsible for many of the contemporary psychosomatic disorders. A. Topitz (Vienna) described one particular disturbance of rhythm, namely, that resulting from air travel in an eastern or western direction. After the Vienna Philharmonic Society's air journey to Tokyo it took its members about four days to become fully adapted to Tokyo local time. He reported similar experiences from several European athletes at the Melbourne Olympic Games.

Applying a principle first introduced by Möllerström to the insulin therapy of diabetes, H. G. Dennemark (Berlin) described clinical experiments demonstrating the importance for therapy of the hour of day at which various drugs and their combinations are administered in the treatment of hypertension.

L. Stark (Newhaven) considered nervous disorders such as tremor, ataxia or clonus as manifestations of inefficient servo-mechanisms. He gavo a description of the working reflex to light of the pupil of the oye in terms of an automatic control device, and showed that certain pathological reactions he found in disseminated sclerosis could be understood by making simple assumptions concerning some parameters of an information loop. H. Drischel (Greifswald) described experiments in which he asked people to synchronize pairs of regular sequences of light flashes, acoustic clicks and taps on the finger tip. Transfer from the periodicity perceived with one sense to another was reasonably accurate within 5-15 hertz, but systematic errors occurred in certain transformations at specific frequencies.

The relation between respiratory, cardiac and vasomotor rhythms was discussed by several speakers : H. P. Koepfchen and K. Thurau (Göttingen) demonstrated curves indicating that the rhythms of vasomotor tonus and of respiration in the rabbit and dog are co-ordinated centrally at a frequency $1: 1$; but showed that other simple proportions of the rhythms occur in exceptional cases. K. Golenhofen (Berlin, Litchterfelde) showed that an analogous situation exists in man by comparing graphs of the rhythmic activity of the peripheral and central blood circulation, and H. Jordan (Bad Elster) demonstrated the presence in periodograms derived from human electrocardiograms of three rhythms, of 12, 28 and 60 sec. average duration, which he considered to be superimposed on the ordinary heart-rhythm.

Other statistical contributions included a paper by K. Freudenberg (Berlin), who presented an extensive collection of data on mortality disproving the belief in the biological importance of every seventh, fourtoenth, twenty-first, etc., year of human life, and a paper by W. Otto (Falkensee) on annual fluctuations in birth weight. The possible importance of seasonal climatic factors, in particular of cold fronts, on asthma attacks and mental symptoms was discussed by S. W. Tromp (Leyden), who also expressed tho hope that meteorological measurements during the current International Geophysical Year might profitably be correlated with detailed clinical observations.

Some fascinating glimpses into the homoestatic mechanics of rhythms wero provided by G. C. Stephens (Minneapolis). Applying temperature changes to proviously established light-controlled rhythms, as had been originally done by Kalmus, he analysed the 24-hr. movements of the melanophore pigment in the fiddler crab, Uca pugnax. Within the temperaturerange $6-26^{\circ} \mathrm{C}$, a $24-\mathrm{hr}$. melanophore periodicity 
persisted in permanent darkness. The phases of induced rhythms could, however, be shifted by sudden changes in temperature provided these exceeded certain threshold values. Delays caused by extreme cooling persisted in darkness and were additive. Individual crabs in which melanophore rhythms of different phase had been induced kept them side by side when transferred to the same darkened aquarium. In spite of this independence of phase it was observed that the amplitude of the melanophore changes was increased by the presence of other fiddler crabs of the same or another species.

Among the papers circulated but not read, that by K. Hoffman (Wilhelmshaven) dealt with the influence of temperature and pretreatment on the 24-hr. motor activity of lizards ; Y. Ondo's (Tottori, Japan) with the responses of shore sowbugs to the periodic movement of waves; E. Szirmay's (Budapest) described some uses of the comparative study of muscle rhythms, and L. S. Copelman's (Bucharest.) dealt with some of the philosophical aspects of biological time.

The International Society for the Investigation of Biological Rhythms, to give it its original name, has now been in existence for twenty years, and at its six conferences a considerable part of the field has been surveyed. More recently the elaboration of general methods for the investigation of bio-rhythms and the formulation of a unifying theory have been attempted.

It is hoped that the full text of the papers will shortly be published. The Society has been invited by Dr. A. Caniggia (Siena) to hold its seventh conference in 1960 in Italy. Inquiries concerning the proceedings, membership and other matters should be addressed to Dr. A. Sollberger, Department of Anatomy, Karolinska Institutet, Stockholm.

H. Kalmus

\section{FLAMMABILITY OF TEXTILES}

$I^{\mathrm{N}}$ $N$ the past few years an increasing amount of publicity has been given to accidents resulting from the burning of elothing, and in the United States legislation has been introduced to prohibit the sale of certain very inflammable types of fabric. In the United Kingdom various safety committees have been set up, and a valuable report on the flammability of apparel fabrics in relation to domestic burning accidents has been published by the British Standards Institution*. It was not surprising, therefore, that the one-day conference, organized by the Textile Institute and dealing with the flammability of textiles, attracted a great deal of attention, for this was probably the first time that mombers of the textile industry, of the distributory trades and of the public were able to meet and discuss together the many aspects of the problem. The conference was held at the laboratories of the Rayon Research Association in Manchester on October 15, and was opened by the president of the Textile Institute, Sir Ernest W. Goodale.

It was evident from the substance of the four papers which formed the basis of the Conference that the seriousness of the high inflammability of certain textiles is widely appreciated and that the textile

- British Standards Institution: PD 2777 (1957). industry is anxious to overcome this hazard. Progress in dealing with the problem has in the past been hindered by lack of precise information, and perhaps the most important feature of the conference was the dissemination of reliable data to replace the lore which is often associated with anything that has to do with fire.

Mr. D. I. Lawson, of the Joint Fire Research Organization, summarized valuable data on the incidence of burning accidents, and his paper emphasized several unexpected observations. Of particular seriousness to the textile industry was the statement that burns involving elothing had the highest mortality-rate of any kind of burn, and that four out of five of the total accidents reported occurred in the home. This is in spite of repeated warnings of the danger from unguarded fires. It was indeed surprising to learn that only half the parents of young children ques. tioned in an investigation had a fireguard. Mr. J. S. Ingham, of Messrs. Marks and Spencer, Ltd., who dealt with the economic aspects of fireproofing and with the possibility of being able to sell fire-proofed garments, also stressed the dangers associated with flared-out dresses and particularly with children's nightdresses made from winceyette.

All the speakers and many members of the conferonce agreed on the need for a publicity campaign to encourage the use of fireguards in homes whore there are young children, and to popularize close-fitting night wear. Mrs. Jean Mann, M.P., speaking from the floor, suggested that the provision of fireguards should be made a condition of house le tting.

The other solution, with which the textile and chemical industries are more directly concerned, is, of course, the provision of safe fabrics. It is difficult to define a 'safe' fabric, for the textile industry and the public must be in agreement about this. One of the first problems, therefore, is to devise a test for inflammability which has some rolation to the practical hazards usually met with. Several of the suggested methods were discussed in detail by Mr. F. Ward, of Courtaulds, Ltd. Mr. Lawson thought that it would be unnecessarily stringent to define as safe only those fabrics which would not ignite when exposed to a radiant source of energy similar to that emitted from the surface of open fires. Measurement of the vertical speed of flamo propaga. tion was generally regarded as being more satisfactory because this gives the length of time available to extinguish the flame or to discard a burning garment. Apparatus for measuring this was described and the term 'flame resistance rating', defined as the time for flame to be propagated 100 in. vertically, was used for expressing the results obtained. Dr. T. H. Morton, of Courtaulds, Ltd., provided a great deal of useful information on how the flame resistance rating is affected by the composition, construction and weight of the fabric, and by the use of special procosses, including some of the modern fireproofing finishes. There are many finishes which will reduce flammability, but for general acceptance other characteristics such as permanence of the proof and the feel of the cloth have also to be considered. 'There was general agreement that any proof used for children's nightdresses should givo flame resistance throughout the life of the garmont, that is, the effect should not be removed by as many as fifty washes.

Clearly one of the most difficult tasks is to define a safe value for the flame resistance rating. Mr. 